\title{
IMPLEMENTASI METODE RECURRENT NEURAL NETWORK PADA TEXT SUMMARIZATION DENGAN TEKNIK ABSTRAKTIF
}

\author{
Kasyfi Ivanedra $^{1}$, Metty Mustikasari ${ }^{2}$ \\ 1,2Teknik Informatika, Universitas Gunadarma \\ Email: ${ }^{1}$ kasyfiivan@gmail.com, ${ }^{2}$ metty@ staff.gunadarma.ac.id
}

(Naskah masuk: 18 September 2018, diterima untuk diterbitkan: 18 Januari 2019)

\begin{abstract}
Abstrak
Text Summarization atau peringkas text merupakan salah satu penerapan Artificial Intelligence (AI) dimana komputer dapat meringkas text pada suatu kalimat atau artikel menjadi lebih sederhana dengan tujuan untuk mempermudah manusia dalam mengambil kesimpulan dari artikel yang panjang tanpa harus membaca secara keseluruhan. Peringkasan teks secara otomatis dengan menggunakan teknik Abstraktif memiliki kemampuan meringkas teks lebih natural sebagaimana manusia meringkas dibandingkan dengan teknik ekstraktif yang hanya menyusun kalimat berdasarkan frekuensi kemunculan kata. Untuk dapat menghasilkan sistem peringkas teks dengan metode abstraktif, membutuhkan metode Recurrent Neural Network (RNN) yang memiliki sistematika perhitungan bobot secara berulang. RNN merupakan bagian dari Deep Learning dimana nilai akurasi yang dihasilkan dapat lebih baik dibandingkan dengan jaringan saraf tiruan sederhana karena bobot yang dihitung akan lebih akurat mendekati persamaan setiap kata. Jenis RNN yang digunakan adalah LSTM (Long Short Term Memory) untuk menutupi kekurangan pada RNN yang tidak dapat menyimpan memori untuk dipilah dan menambahkan mekanisme Attention agar setiap kata dapat lebih fokus pada konteks. Penelitian ini menguji performa sistem menggunakan Precision, Recall, dan F-Measure dengan membandingan hasil ringkasan yang dihasilkan oleh sistem dan ringkasan yang dibuat oleh manusia. Dataset yang digunakan adalah data artikel berita dengan jumlah total artikel sebanyak 4515 buah artikel. Pengujian dibagi berdasarkan data dengan menggunakan Stemming dan dengan teknik Non-stemming. Nilai rata-rata recall artikel berita nonstemming adalah sebesar $41 \%$, precision sebesar $81 \%$, dan F-measure sebesar $54,27 \%$. Sedangkan nilai ratarata recall artikel berita dengan teknik stemming sebesar 44\%, precision sebesar 88\%, dan F-measure sebesar $58,20 \%$.
\end{abstract}

Kata kunci: Text Summarization, Recurrent Neural Network, Abstraktif, Deep Learning, LSTM.

\section{THE IMPLEMENTATION OF TEXT SUMMARIZATION WITH ABSTRACTIVE TECHNIQUES USING RECURRENT NEURAL NETWORK METHOD}

\begin{abstract}
Text Summarization is the application of Artificial Intelligence (AI) where the computer can summarize text of article to make it easier for humans to draw conclusions from long articles without having to read entirely. Abstractive techniques has ability to summarize the text more naturally as humans summarize. The summary results from abstractive techinques are more in context when compared to extractive techniques which only arrange sentences based on the frequency of occurrence of the word. To be able to produce a text summarization system with an abstractive techniques, it is required Deep Learning by using the Recurrent Neural Network $(R N N)$ rather than simple Artificial Neural Network (ANN) method which has a systematic calculation of weight repeatedly in order to improve accuracy. The type of RNN used is LSTM (Long Short Term Memory) to cover the shortcomings of the RNN which cannot store memory to be sorted and add an Attention mechanism so that each word can focus more on the context.This study examines the performance of Precision, Recall, and F-Measure from the comparison of the summary results produced by the system and summaries made by humans. The dataset used is news article data with 4515 articles. Testing was divided based on data using Stemming and Non-stemming techniques. The average recall value of non-stemming news articles is $41 \%$, precision is $81 \%$, and F-measure is $54.27 \%$. While the average value of recall of news articles with stemming technique is $44 \%$, precision is $88 \%$, and $\mathrm{F}$-measure is $58.20 \%$.
\end{abstract}

Keywords: Text Summarization, Recurrent Neural Network, Abstractive, Deep Learning, LSTM. 


\section{PENDAHULUAN}

Seiring dengan perkembangan data pada internet yang tumbuh dengan pesat, informasi yang tersedia pada dunia internet sangatlah berlimpah dengan jumlah penulisan dan teks yang begitu besar dan panjang. Untuk mempermudah manusia, maka dibutuhkan suatu alat yang dinamakan peringkas teks otomatis atau Text Summarization. Peringkas teks otomatis bertujuan untuk menghasilkan suatu ringkasan dari teks panjang yang diberikan. Dengan menggunakan peringkas teks otomatis, manusia dapat menerima informasi dari teks yang begitu panjang hanya dalam waktu singkat sehingga dapat mempersingkat waktu yang dibutuhkan dibandingkan dengan membaca keseluruhan informasi yang diinginkan (Khan \& Naomie, 2014).

Untuk mewujudkan peringkas teks otomatis, dibutuhkan teknik yang terbagi menjadi dua, yaitu peringkasan dengan teknik Ekstraktif dan teknik Abstraktif. Teknik ekstraktif mengambil setiap kata pada teks asal lalu dikelompokkan dan disusun tanpa mengubah kata asal. Biasanya kalimat yang dihasilkan tersusun sama dengan kalimat pada dokumen asal (Prabowo, 2016). Teknik abstraktif memiliki tujuan untuk menghasilkan kalimat ringkasan dengan konsep sebagaimana manusia mengambil intisari dari sebuah dokumen yang dibaca (Khan \& Naomie, 2014). Dengan begitu, kalimat yang dihasilkan akan terkesan lebih simpel, alami, dan tidak kaku.

Untuk dapat menerapkan peringkas teks otomatis secara abstraktif dibutuhkan perhitungan yang lebih dalam mencari persamaan setiap kata sehingga menghasilkan ringkasan. Untuk itu dibutuhkan pendekatan Deep Learning. Dengan deep learning, input akan dihitung melalui layer yang lebih banyak dibandingkan JST sederhana (Goodfellow, 2016). RNN merupakan penerapan deep learning yang digunakan.

Penggunaan metode RNN untuk peringkas teks otomatis diawali dari keberhasilan pemecahan masalah untuk mesin translasi kata (Nallapati et al, 2016). RNN diharapkan dapat menghasilkan model yang dapat menghasilkan teks ringkasan secara abstrak. Selain menggunakan RNN, model membutuhkan arsitektur tambahan yaitu attention (Bahdanau, 2014). Arsitektur ini berfungsi untuk memfokuskan setiap kata yang masuk ke sel RNN pada target output sehingga hasil dapat sesuai dengan konteks dokumen asal.

Penelitian yang dilakukan oleh Nedunchelian Ramanujam dan Manivannan Kaliappan menggunakan Naive Bayesian Classifier (NBC) sebagai metode utama dalam menghasilkan model peringkas teks otomatis dalam bentuk ekstraktif. Metode NBC menggunakan teknik perhitungan frekuensi kata. Kata dengan frekuensi terbanyak akan dipilih untuk dijadikan kalimat baru berupa ringkasan. Metode NBC dapat ditingkatkan dengan teknik abstraktif untuk menghasilkan ringkasan yang lebih pendek. Kelemahan metode ekstraktif ini adalah pada hasil ringkasan yang cenderung lebih kaku dan tidak alami. Hasil ringkasan hanya berupa perpaduan kalimat-kalimat terpilih dengan frekuensi kemunculan terbanyak sehingga terkadang tidak sesuai dengan konteks kalimat awal (Ramanujam, 2016). Sedangkan penelitian oleh C. Sunitha menjelaskan perbedaan antara metode ekstraktif dan abstraktif. Metode abstraktif dapat menghasilkan ringkasan yang dinilai lebih tepat, komplit, dan lebih bermakna dibandingkan dengan metode ekstraktif. Metode abstraktif juga dapat mengurangi redudansi pada konsep dan relasi antar kata sehingga ringkasan dapat lebih tepat sesuai konteks (Sunitha, 2016).

Pada paper SummaRuNNer: A Recurrent Neural Network Based Sequence Model for Extractive Summarization of Documents, metode yang digunakan adalah RNN dengan teknik ekstraktif. RNN digunakan untuk mencari hubungan antara kata dari banyaknya frekuensi kata yang muncul. Sedangkan dengan LSTM, memiliki mekanisme yang lebih mengedepankan memori dari langkah pelatihan sebelumnya untuk mendapatkan hubungan antar kata sehingga ideal untuk memproses text speech, translation, dan summarization (Nallapati,dkk, 2016).

Paper ini terdiri dari 5 bab, dimulai dari pendahuluan menjelaskan secara global penggunan metode LSTM. Dasar teori pada bab 2 menjelaskan teori-teori yang digunakan pada penulisan. Bab 3 berisikan metode penelitian yang digunakan. Hasil pengujian dan evaluasi dijelaskan pada bab 4 dan bab 5 berisikan kesimpulan serta saran.

\section{METODE PENELITIAN}

Metode penelitian yang dilakukan ditampilkan pada Gambar 2.

Metode dimulai dari mempersiapkan dataset yang digunakan sebagai data latih. Lalu data tersebut diolah agar menjadi data yang memiliki makna pada tahap pra-proses data. Pra-proses data memiliki tahapan mulai dari tokenisasi, mengubah kata menjadi lower case, stopword removal, dan stemming (Johnston, 2013). Kata diubah menjadi vektor dalam proses vektorisasi. Model dibangun dengan menggunakan metode yang menjadi variansi dari RNN yaitu LSTM (Long Short Term Memory). Model tersebut digunakan untuk melatih data yang sudah dalam bentuk vektor. Setelah pelatihan selesai, dilakukan uji coba peringkasan teks. Tahap terakhir adalah evaluasi terhadap keakuratan model yang sudah dibuat.

Metode dimulai dari mempersiapkan dataset yang digunakan sebagai data latih. Lalu data tersebut diolah agar menjadi data yang memiliki makna pada tahap pra-proses data. Pra-proses data memiliki tahapan mulai dari tokenisasi, mengubah kata menjadi lower case, stopword removal, dan stemming (Johnston, 2013). Kata diubah menjadi vektor dalam proses vektorisasi. Model dibangun 
dengan menggunakan metode yang menjadi variansi dari RNN yaitu LSTM (Long Short Term Memory). Model tersebut digunakan untuk melatih data yang sudah dalam bentuk vektor. Setelah pelatihan selesai, dilakukan uji coba peringkasan teks. Tahap terakhir adalah evaluasi terhadap keakuratan model yang sudah dibuat.

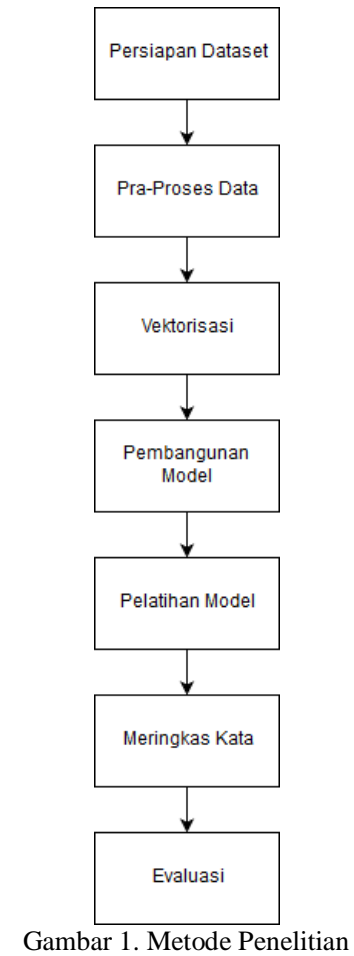

\subsection{Spesifikasi Hardware}

Hardware yang digunakan sebagai pelatihan adalah sebagai berikut:

Tabel 2. Spesifikasi Hardware

\begin{tabular}{ll}
\hline \multicolumn{1}{c}{ Perangkat } & \multicolumn{1}{c}{ Spesifikasi } \\
\hline Laptop Notebook & Acer Aspire E14 dengan tipe \\
& E5-475G \\
Prosesor & Intel Core i5-7200U 2.5GHz \\
RAM & 4GB bertipe DDR4 \\
Grafik & NVIDIA GeForce 940MX \\
\hline
\end{tabular}

\subsection{Pra-Proses Data}

Tahap awal dari pengerjaan program adalah dengan menyiapkan sejumlah data yang akan digunakan sebagai bahan pembelajaran oleh komputer. Data inilah yang menjadi acuan bagaimana model akan terbentuk. Tahap yang akan dilakukan pada pra-proses adalah tokenisasi, mengubah kata menjadi lower case, stopword removal, dan stemming.

\subsection{Vektorisasi}

Pada tahap ini, kata yang sudah dibersihkan dan siap digunakan diubah terlebih dahulu menjadi vektor dengan tujuan agar kata dapat dihitung dan memiliki nilai persamaan antara satu kata dengan kata yang lain. Vektorisasi pada penelitian ini menggunakan vektor yang sudah diolah sebelumnya (pra-proses).

\subsection{Pembangunan Model}

Metode yang digunakan adalah dengan menerapkan Jaringan Syaraf Tiruan atau yang dikenal dengan istilah Neural Network. Jaringan syaraf tiruan memiliki sistem kerja yang menyerupai kerja syaraf di otak manusia. Setiap jaringan memiliki input layer, hidden layer, dan output layer (Daniel, 2013).

Salah satu jenis NN adalah Recurrent Neural Network atau bisa disebut RNN. Jaringan ini memiliki sedikit perbedaan daripada jaringan NN biasa. Jika pada NN, setiap input akan masuk lalu melalui hidden layer dan mengeluarkan output, sedangkan pada RNN terdapat perulangan. Setiap input yang masuk dan menghasilkan output, akan masuk kembali menjadi input untuk diproses di dalam hidden layer (Graves, 2012). Begitu seterusnya sehingga memperoleh output sesuai dengan target.

Model dibangun dengan metode RNN secara $b i$ diectional atau perhitungan bobot pada RNN secara bolak-balik. Jenis variansi RNN yang digunakan adalah LSTM yang mmiliki kemampuan untuk mengolah informasi lebih akurat (Zhang, 2016). LSTM memiliki kelebihan daripada sekedar RNN biasa, yaitu adanya arsitektur mengingat dan melupakan output yang akan diproses kembali menjadi input. Selain itu, kemampuan LSTM yang lain adalah dapat mempertahankan error yang terjadi ketika melakukan backpropagation sehingga tidak memungkinkan kesalahan meningkat (Zhang, 2016; Fauzi, 2016).

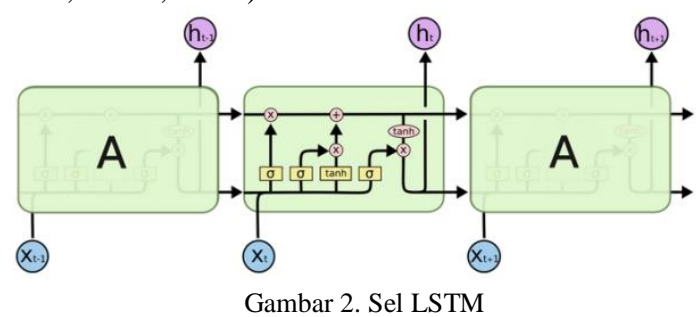

Mekanisme attention digunakan untuk memfokuskan setiap hasil output LSTM terhadap target kata. Dengan attention, kata yang dihasilkan memiliki hubungan yang lebih baik sehingga lebih sesuai dengan konteks (Bahdanau et al, 2014).

Model memiliki beberapa hyperparameter yang digunakan (Greff, 2017). Learning rate minimal yang digunakan adalah 0.005 dengan jeda senilai 0.95. Epoch sebanyak 100 kali. Ukuran batch yang digunakan sebesar 64 dan ukuran RNN sel nya adalah 256, serta menggunakan 2 layer. 


\subsection{Pelatihan Data}

Pada tahap training, data yang sudah siap untuk digunakan akan terlebih dahulu diubah menjadi vektor pada word embedding. Lalu input tersebut akan diolah pada encoder layer. Pada encoder layer, sel LSTM akan memproses input sehingga menghasilkan output yang akan diteruskan ke hidden layer. Pada hidden layer, data yang dilatih akan dicatat dalam bentuk logistik untuk memperbaharui weight dan nilai yang dibutuhkan agar mencapai target output. Decoder layer akan menerima hasil dari hidden layer untuk kemudian difokuskan menggunakan attention sehingga mendapatkan bobot nilai yang mendekati nilai target output. Lalu bentuk vector akan diubah kembali menjadi teks untuk kemudian ditampilkan sebagai output teks.

\subsection{Peringkasan Kata}

Setelah model dilatih, maka tahap terakhir adalah melakukan test terhadap kalimat yang diinput kedalam jaringan. Kalimat akan diproses menggunakan model yang sudah dihasilkan oleh tahap training untuk menghasilkan hasil ringkasan.

\section{HASIL PENGUJIAN DAN EVALUASI}

\subsection{Persiapan Dataset}

Dataset yang adalah dataset news atau berita yang berisi kumpulan dari artikel berita Hindu, Indian Times, dan Guardian. Dataset ini terdiri dari 4515 buah artikel beserta ringkasan teks sebagai target output. Semua jumlah dataset digunakan untuk bagian pelatihan dan test.

\subsection{Hasil Pelatihan Data}

Tahap pelatihan atau training dilakukan dirangkum pada Tabel 3 berikut:

\begin{tabular}{ccccc}
\multicolumn{4}{c}{ Tabel 3. Training model dengan dataset } & \\
\cline { 1 - 4 } Dataset & $\begin{array}{c}\text { Banyak } \\
\text { Data }\end{array}$ & $\begin{array}{c}\text { Waktu } \\
\text { Latih }\end{array}$ & Epoch & Loss \\
\cline { 1 - 3 } $\begin{array}{c}\text { Non- } \\
\text { Stem }\end{array}$ & 1959 & $\begin{array}{c}\text { 1 Jam 15 } \\
\text { menit }\end{array}$ & $51 / 100$ & 0.32 \\
Stem & 729 & 35 menit & $24 / 100$ & 0.34 \\
\hline
\end{tabular}

Dari uji coba pelatihan pada model, dataset yang menggunakan teknik stemming selesai lebih cepat dibandingkan dengan dataset non-stemming. Tetapi loss yang dihasilkan dataset non- stemming lebih sedikit dibandingkan dengan artikel berita yang menggunakan stemming. Jumlah data berpengaruh terhadap waktu training. Proses training disajikan dalam bentuk grafik Gambar 3 dan 4, dimana rata-rata loss berbanding dengan berapa kali epoch yang dilakukan.

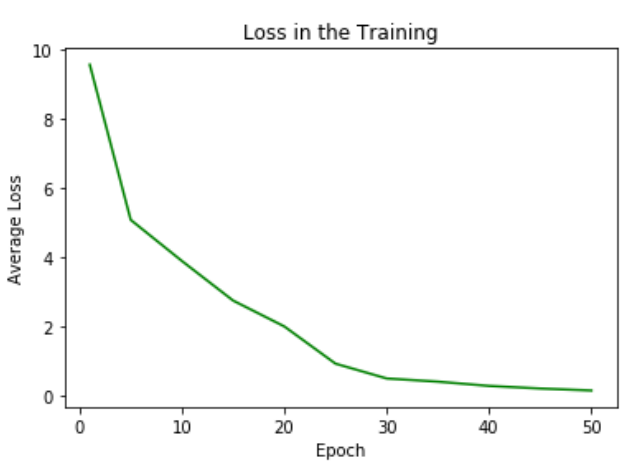

Gambar 3. Grafik Training Artikel Non-Stemming

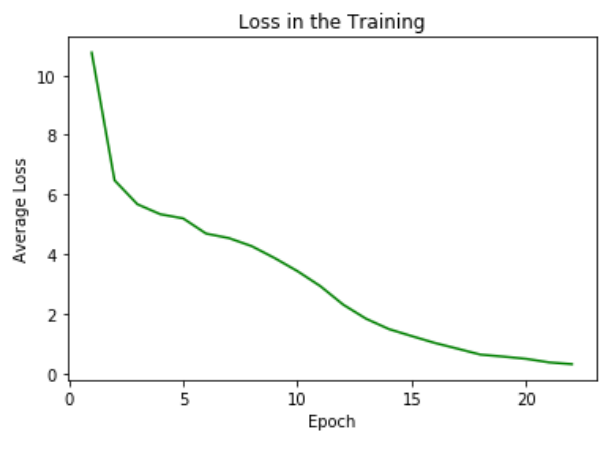

Gambar 4. Grafik Training Artikel Stemming

\subsection{Hasil Ringkasan}

Langkah berikutnya adalah melakukan peringkasan oleh model yang sudah dilatih. Pengujian menggunakan data sebanyak 3 buah teks berbahasa Inggris dan masing-masing artikel diuji terhadap dataset yang berbeda. Ringkasan yang dihasilkan oleh model dibandingkan dengan hasil ringkasan oleh manusia yaitu sebuah kalimat dengan jumlah maksimal 12 kata. Hasil ringkasan disajikan dalam bentuk Tabel 4, Tabel 5, dan Tabel 6 berikut:

\begin{tabular}{ll} 
& Tabel 4. Hasil Ringkasan Teks 1 \\
\hline Artikel & 1 \\
Teks Asal & Pakistan-born London terrorist \\
& Khuram Butt, who masterminded last \\
& Saturday's London Bridge attack, was \\
& trying to land a job with a firm that \\
& provides security at Wimbledon and \\
& other sporting events. The 27-year-old \\
& had previously worked six months \\
& with the London Underground metro \\
& before quitting in October. Butt and his \\
& aides rammed a high-speed van into \\
& pedestrians on the London Bridge.
\end{tabular}

Artikel Berita pak born london terrorist trying

non-stemming

Artikel Berita pak born london terrorist tri 
Tabel 5. Hasil Ringkasan Teks 2

\begin{tabular}{|c|c|}
\hline Artikel & 2 \\
\hline Teks Asal & $\begin{array}{l}\text { 'Harry Potter' actor Daniel Radcliffe } \\
\text { helped a tourist who was attacked by } \\
\text { two men on bikes in London. The } \\
\text { victim was walking when the men } \\
\text { stole his bag and left him with an } \\
\text { injury. "He was a really nice bloke, a } \\
\text { lot of stars wouldn't have stopped to } \\
\text { help," said a former policeman who } \\
\text { tried to intervene during the robbery. }\end{array}$ \\
\hline $\begin{array}{l}\text { Artikel Berita } \\
\text { non-stemming }\end{array}$ & harry potter actor daniel play \\
\hline $\begin{array}{l}\text { Artikel Berita } \\
\text { stemming }\end{array}$ & harri potter actor daniel help \\
\hline \multicolumn{2}{|c|}{ Tabel 6. Hasil Ringkasan Teks 3} \\
\hline Artikel & 3 \\
\hline Teks Asal & $\begin{array}{l}\text { Filmmaker Christopher Nolan has } \\
\text { revealed that he watched the Oscar- } \\
\text { winning film 'La La Land' thrice. He } \\
\text { added, 'I think I almost went back to } \\
\text { see if it was as good as I had thought, } \\
\text { and it was.' Notably, the Emma Stone } \\
\text { and Ryan Gosling starrer 'La La Land' } \\
\text { won six Oscar Awards and received a } \\
\text { record fourteen Oscar nominations. }\end{array}$ \\
\hline $\begin{array}{l}\text { Artikel Berita } \\
\text { non-stemming } \\
\text { Artikel Berita } \\
\text { stemming }\end{array}$ & $\begin{array}{l}\text { christopher nolan reveals watched la } \\
\text { la } \\
\text { christoph nolan reveal watch la la }\end{array}$ \\
\hline
\end{tabular}

\subsection{Hasil Evaluasi}

Metode pengujian menggunakan metode intrinsik. Metode intrinsik yang digunakan adalah content evaluation.Metode ini menghitung akurasi dengan mencari nilai precision, recall, dan $F$ Measure (Steinberg, 2009); (Ramanujam, 2016). Precision merupakan pengukuran tingkat ketepatan hasil ringkasan yang dihasilkan oleh peringkas teks otomatis. Precision juga mengukur relevansi peluang teks yang terambil sebagai ringkasan. Recall merupakan pengukuran tingkat keberhasilan ringkasan yang dihasilkan peringkas teks otomatis. Recall juga dapat mengukur peluang teks relevan yang terambil sebagai ringkasan. Sedangkan $F$ Measure merupakan nilai yang digunakan untuk mengukur akurasi dari ringkasan yang dihasilkan.

$$
\begin{aligned}
& \text { Recall }=\frac{\sum \text { Kata Relevan }}{\sum \text { Kata ringkasan Manual }} \\
& \text { Precision }=\frac{\sum \text { Kata Relevan }}{\sum \text { Kataringkasan Sistem }} \\
& F-\text { Measure }=\frac{2 \times \text { Recall } \times \text { Precision }}{\text { Recall }+ \text { Precision }}
\end{aligned}
$$

Kata relevan merupakan kata-kata pada ringkasan yang dihasilkan oleh peringkas teks otomatis sama dengan kata-kata yang dihasilkan secara manual oleh manusia. Untuk mendapatkan nilai recall, maka kata relevan dibagi dengan jumlah kata pada ringkasan manual. Untuk mendapatkan nilai precision, maka kata relevan dibagi dengan jumlah kata pada ringkasan sistem. Sedangkan untuk mendapatkan nilai akurasi dari ringkasan, dengan mencari nilai F-Measure, yaitu berdasarkan nilai recall dan nilai precision (Steinberg, 2009).

Ringkasan manual didapat dengan memberikan kusioner terhadap 5 orang yang memiliki kemampuan memahami teks dalam bahasa inggris dengan baik. Ringkasan manual yang dihasilkan maksimal 12 kata. Ringkasan manual yang akan digunakan sebagai ringkasan perbandingan adalah ringkasan yang memiliki kata yang sama dengan frekuensi tertinggi yang sudah dihasilkan oleh kelima responden.

Tabel 7. Uji Evaluasi Perbandingan Teks Ringkasan

\begin{tabular}{cccccc} 
Teks & $\sum_{\text {KRM }}$ & $\sum_{\text {KRS }}$ & $\begin{array}{c}\sum \text { KRS } \\
\mathbf{2}\end{array}$ & KR & KR 2 \\
\hline 1 & 10 & 5 & 5 & 4 & 4 \\
2 & 12 & 5 & 5 & 4 & 5 \\
3 & 10 & 6 & 6 & 5 & 5 \\
\hline
\end{tabular}

Keterangan:

$\begin{array}{ll}\mathrm{KRM}= & \text { Kata Ringkasan Manual } \\ \mathrm{KRS}= & \text { Kata Ringkasan Sistem Non- } \\ \text { Stemming } & \\ \mathrm{KRS} 2= & \text { Kata Ringkasan Sistem stemming } \\ \mathrm{KR}= & \text { Kata Relevan Non-stemming } \\ \mathrm{KR} 2= & \text { Kata Relevan stemming }\end{array}$

Hasil ringkasan sistem dibandingkan dengan hasil ringkasan manual untuk mendapatkan nilai precision berdasarkan persamaan (2), recall berdasarkan persamaan (1), dan F-measure berdasarkan persamaan (3). Nilai akurasi tersebut dirangkum pada tabel 6 dan 7 berikut:

Tabel 8. Hasil Evaluasi Metode Intrinsik pada Artikel Non-

\begin{tabular}{cccc}
\multicolumn{4}{c}{ Stemming } \\
\hline Teks & $\begin{array}{c}\text { Recall } \\
(\boldsymbol{\%})\end{array}$ & $\begin{array}{c}\text { Precision } \\
(\boldsymbol{\%})\end{array}$ & $\begin{array}{c}\text { F-Measure } \\
(\boldsymbol{\%})\end{array}$ \\
\hline 1 & $40 \%$ & $80 \%$ & $53,3 \%$ \\
2 & $33,3 \%$ & $80 \%$ & $47 \%$ \\
3 & $50 \%$ & $83,3 \%$ & $62,5 \%$ \\
$\begin{array}{c}\text { Rata- } \\
\text { Rata }\end{array}$ & $\mathbf{4 1 \%}$ & $\mathbf{8 1 \%}$ & $\mathbf{5 4 , 2 7 \%}$ \\
\hline
\end{tabular}

Tabel 9. Hasil Evaluasi Metode Intrinsik pada Artikel Stemming

\begin{tabular}{cccc}
\hline Teks & $\begin{array}{c}\text { Recall } \\
(\boldsymbol{\%})\end{array}$ & $\begin{array}{c}\text { Precision } \\
(\boldsymbol{\%})\end{array}$ & $\begin{array}{c}\text { F-Measure } \\
(\boldsymbol{\%})\end{array}$ \\
\hline 1 & $40 \%$ & $80 \%$ & $53,3 \%$ \\
2 & $41,6 \%$ & $100 \%$ & $58,8 \%$ \\
3 & $50 \%$ & $83,3 \%$ & $62,5 \%$ \\
$\begin{array}{c}\text { Rata- } \\
\text { Rata }\end{array}$ & $\mathbf{4 4 \%}$ & $\mathbf{8 8 \%}$ & $\mathbf{5 8 , 2 0 \%}$ \\
\hline
\end{tabular}

Dari tahapan pengujian evaluasi yang telah dilakukan terhadap peringkas teks otomatis dengan menggunakan metode intrinsik, dapat diketahui bahwa nilai rata-rata recall artikel berita nonstemming adalah sebesar $41 \%$, precision sebesar 
$81 \%$, dan F-measure sebesar 54,27\%. Sedangkan nilai rata-rata recall artikel berita dengan teknik stemming sebesar $44 \%$, precision sebesar $88 \%$, dan F-measure sebesar 58,20\%.

\section{KESIMPULAN DAN SARAN}

\subsection{Kesimpulan}

Setelah melakukan pengujian dan evaluasi terhadap peringkas teks otomatis, ada beberapa poin yang dapat disimpulkan. Perbedaan jumlah dataset yang digunakan sebagai bahan training sangat berpengaruh, karena pembendaharaan kata yang lebih banyak tentunya menjadikan program lebih mengerti dan lebih akurat dalam menciptakan ringkasan. Nilai rata-rata recall artikel berita nonstemming adalah sebesar $41 \%$, precision sebesar $81 \%$, dan F-measure sebesar 54,27\%. Sedangkan nilai rata-rata recall artikel berita dengan teknik stemming sebesar $44 \%$, precision sebesar $88 \%$, dan F-measure sebesar 58,20\%.

\subsection{Saran}

Penambahan jumlah pada dataset yang akan digunakan dapat mempengaruhi hasil ringkasan. Semakin banyak data yang dilatih, maka semakin 'pintar' pula program peringkas teks, karena program memiliki perbendaharaan yang banyak dari berbagai macam contoh ringkasan data. Disamping itu, untuk menghasilkan data yang lebih layak untuk digunakan dapat ditambah dengan menggunakan teknik lemmatize agar hasil ringkasan dapat dengan fokus menghasilkan kalimat yang sesuai dengan konteks.

\section{DAFTAR PUSTAKA}

BAHDANAU, DZMITRY., CHO, KYUNGHYUN., \& BENGIO, YOSHUA., 2014. Neural Machine Translation by Jointly Learning to Align and Translate. CoRR, abs/1409.0473. Conference ICLR.

C. SUNITHA., JAYA, DR.A., GANESH, AMAL., 2016, A study on Abstractive Summarization Techniques in Indian Language, Fourth International Conference on Recent Trends in Computer Science \& Engineering, Elsevier B.V, pp.25-31.

DANIEL, GRAUPE, 2013, Principles of Artificial Neural Network (3 ${ }^{\text {rd }}$ Edition), Word Scientific, Singapore.

FAUZI, RAHMAT, 2016, Implementasi Jaringan Syaraf Tiruan dengan Metode Backpropagation terhadap Bibit Tanaman Karet. Jurnal Education and Development STKIP Tapanuli Selatan, pp. 1-11.

GOODFELLOW, IAN., BENGIO, YOSHUA., \& COURVILlE, AARON., 2016, Deep Learning, MIT Press Cambridge, Inggris.
GREFF, KALUS., SRIVASTAVA, RUPESH K., KOUTNNIK, JAN., STEUNEBRINK, BAS R., SCHMIDDHUBER, JURGEN., 2017. LSTM: A Search Space Odyssey. Transactions on Neural Network and Learning System.

JOHNSTON, LINDSAY, 2013, Data Mining: Concepts, Methodologies, Tools, and Applications, Vol 1, Information Science Reference, USA.

KHAN, ATIF \& NAOMIE SALIM, 2014. A Review on Abstractive Summarization Methods. Journal of Theoretical and Applied Information Techonlogy, pp.64-71.

NALLAPATI, RAMESH., ZHAI, FEIFEI., ZHOU, BOWEN, 2016. SummaRuNNer: A Recurrent Neural Network Based Sequence Model for Extractive Summarization of Documents. The Thirty-First AAAI Conference on Artificial Intelligence (AAAI-2017)

NALLAPATI, RAMESH., ZHOU, BOWEN., SANTOS, DOS CICERO., GULCEHRE, CAGLAR., \& XIANG, BING., 2016. Abstractive Text Summarization using Sequence-to-sequence RNNs and Beyond. The SIGNLL Conference on Computational Natural Language Learning (CoNLL)

PRABOWO, D.A., FHADLI, M., NAJIB, M.A., FAUZI, H.A., \& CHOLISSODIN, IMAM., 2016. TF-IDF-Enchanted Genetic Algorihm untuk Extractive Automatic Text Summarization, Vol 3, No. 3, Jurnal Teknologi Informasi dan Ilmu Komputer (JTIIK), pp.208-215.

RAMANUJAM, N \& KALIAPPAN, M, 2016, An Automatic Multidocument Text Summarization Approach Based on Nä̈ve Bayesian Classifier Using Timestamp Strategy, The Scientific World Journal, Hindawi Publishing, pp.1-10.

STEINBERG, J. \& JEZEK, K., 2009, Evaluation Measures for Text Summarization, Computing and Informatics, vol. 28, no.2, pp. 251-275.

ZHANG, LIN, 2016, Theory, Methodology, Tools, and Applications for Modeling and Simulation of Complex Systems, Springer + Business Media, Singapore. 